\title{
Assistência Médico-Sanitária: Notas para uma Avaliação
}

* Depto. de Administração e Planejamento em Saúde da Escola Nacional de Saude Pública/Fiocruz Rua Leopoldo Bulhöes, 1480, 7 andar, Manguinhos, 21041 - Rio de Janeiro - $R J$
Eliane dos Santos de Oliveira*

$O$ artigo apresenta a pesquisa Assistência Médico-Sanitária, AMS, desenvolvida pelo IBGE, com objetivo de discutir o papel desta pesquisa no Processo da Reforma Sanitária. Ressalta a importância de uma maior interação entre o IBGE $e$ usuário, para que haja uma explicitação mais clara das reais necessidades do usuário $e$, com isso, um melhor aproveitamento das informações disponiveis.

$E$, por fim, sugere um aperfeiçoamento na divulgaçāo das pesquisas e ao acesso do banco de dados do IBGE, tendo em vista que estes constituem um dos grandes bloqueios no processo de planejamento no setor saúde.

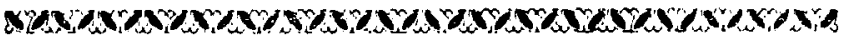

\section{INTRODUÇĀO}

O propósito desse trabalho é o de fazer uma avaliação global da AMS, como instrumento de dados. Essa avaliação se situa no contexto de uma preocupação mais ampla com as necessidades de informações para a área da saúde. Trata-se de uma primeira aproximação parcial, cuja finalidade principal se realizaria no despertar de um debate mais abrangente e contínuo sobre o sistema de informações existentes no Brasil.

A premissa central norteando essas reflexōes é de que, na atual conjuntura, o próprio sistema de informações merecia ser repensado no seu conjunto.

$O$ instrumento de coleta já tem uns quatro anos e precisaria ser reavaliado à luz da evolução do sistema e das prioridades de distintos tipos de informação, para a nova estrutura do sistema de saúde que vem sendo implantado no Brasil (SUDS).

\section{A ORIGEM E A EVOLUÇÃO DA AMS}

Para situar o lugar da AMS no sistema brasileiro de informações de saúde, é preciso recordar que ela foi ini- 
cialmente gestada e desenvolvida dentro do Ministério da Saúde, quando este foi criado, em 1953. Na pesquisa, eram utilizados dois formulários distintos, um para a parte "Assistencial Hospitalar e Para-Hospitalar" "e outro para "Serviços Oficiais de Saúde Pública" ". Com a crescente demanda de informações estatísticas na área de saúde, o Ministério da Saúde e a Fundação IBGE firmaram um convênio estabelecendo que, a partir de 1975, o IBGE assumiria os encargos da coleta, apuração, sistematização e divulgação dos dados da pesquisa de saúde.

Já em 1976, o título da pesquisa passou a ser "Assistência Médico-Sanitária" (AMS), sendo utilizado somente um questionário que, no IBGE, sofreu várias alterações. nos anos seguintes.

Em 1985, com o intuito de se avaliarem as estatísticas de saúde que vinham sendo apuradas e de se certificarem se realmente elas estavam atendendo às demandas específicas do setor saúde, a pesquisa foi totalmente reformulada, com o propósito de fornecer elementos para a construção de indicadores de saúde que subsidiariam as novas políticas de saúde: neste processo de renovação da pesquisa, os principais usuários foram consultados, dentre eles a Fiocruz, Inamps, ENSP, Secretarias Estaduais de Saúde, Opas e Unicef, o que de alguma forma fortaleceu a pesquisa de Assistência Médico-Sanitária, com a assinatura de convênio com o Inamps, que repassou verba específica para a pesquisa, e com a Fiocruz, para intercâmbio de informações.

Ressaltamos que, atualmente, o IBGE é o principal órgão em informações na área da oferta de serviços de saúde, já que a pesquisa cadastrou 32.450 estabelecimentos, no ano base de 1987.

De 1985 a 1987, a pesquisa AMS manteve-se inalterada. Somente no ano base de 1988, foram substituidos os dois instrumentos de coleta (questionário geral - QG - e a FAC-formulário de atualização cadastral), por um único formulário - FAB (formulário de atualização básica), que contemplava somente os dados elementares, que freqüentemente sofrem alterações de ano para ano.

Fez-se necessária esta mudança devido a graves problemas de distribuição de recursos dentro do IBGE e à reflexão pelo uso dos mesmos instrumentos durante o triênio. Outro fato importante que contribui para contextualizar o momento foi a nova estrutura do setor saúde, que viabilizou uma dinâmica no arcabouço jurídico-institucional, que cer-
*Estabelecimentos Hospitalares - com a finalidade primordial de prestar assistência médica em regime de internação, exigindo a assistência médica permanente; Estabelecimentos Para-Hospitalares - com a finalidade principal de prestar assistência médica em regime de não-internação.

**Serviços Oficiais de Saúde Pública - estabelecimentos que promovem a prevenção das doenças (postos de saúde, centro de saúde, preventório contra a lepra e tuberculose). 
tamente afetará as estatisticas de saúde até hoje produzidas no Brasil.

Em resumo, sugerimos que o atual sistema de informação para a área de saúde mereça ser repensado à luz das mudanças no contexto histórico do pais frente ao SUDS. E, para se tentar dimensionar e qualificar o uso de informações, especificamente em relação às questões da AMS, sugerimos que sejam feitas as seguintes reflexões:

A - Quem faz uso das informaçōes das AMS? Em que sentido e até que ponto as informações produzidas pela AMS sobre Estabelecimentos e Pessoal de Saúde, motivo central da realização da AMS anualmente, são imprescindiveis, face ao seu uso real e as suas limitaçōes?

B - Qual é a relação custo/benefício da geração, processamento e utilização dos dados da AMS? Quanto custa a realização de uma AMS? Quantas pessoas, grupos ou instituições utilizam, efetivamente, os dados da AMS e para que finalidades? O grau de utilização das informações da AMS é, em termos globais, mensurável com o gasto efetuado na pesquisa?

C - Quais são as principais deficiências e necessidades de informação contínuas não preenchidas pela AMS? Ou seja, que tipo de dados os pesquisadores, planejadores necessitariam com maior urgência?

Infelizmente a concepção de um constante intercâmbio entre produtor e usuários de dados ainda é pouco desenvolvida no Brasil.

O IBGE é, sem dúvida alguma, o principal produtor de informações e é, em determinados casos, o seu maior usuário; talvez essa relação "incestuosa" tenha prejudicado o estreitamento da relação entre produtos e usuários externos.

Seja como for, o fato é que não se tem no Brasil uma noção, por mais imprecisa que seja, de quem faz uso das informações produzidas em qualquer área.

\section{OBJETIVO DA PESQUISA}

O Objetivo é gerar dados que permitam construir niveis de complexidade dos estabelecimentos prestadores dos serviços de saúde e fornecer subsídios para:

- Orientar a política dos recursos humanos na área de saúde. 
- O planejamento de saúde, o financiamento do setor e aplicação dos recursos da rede vinculada à Previdência Social.

- Construir indicadores de saúde, tais como: nascidos vivos, mortalidade geral e infantil.

- Estabelecer base para unificação das informações do setor saúde.

\section{ÃMBITO DA PESQUTSA}

A pesquisa é de âmbito nacional e realizada anualmante, estando todos os estabelecimentos que prestam serviço de saúde, com ou sem fins lucrativos, privados ou públicos, obrigados ao preenchimento do questionário. Dentre eles destacamos:

a) Posto de Saúde.

b) Centro de Saúde.

c) Clínica ou Posto de Assistência Médica - PAM.

d) Pronto Socorro.

e) Unidade Mista.

f) Hospital.

Não são incluídos no levantamento:

a) Consultórios médicos e/ou dentários particulares.

b) Ambulatórios médicos e/ou gabinetes dentários da rede escolar, de instituições de amparo aos menores e à velhice e de empresas particulares e/ou de entidades públicas que se destinem exclusivamente ao atendimento de seus empregados e dependentes.

c) Laboratórios de análises clínicas.

d) Clínicas radiológicas.

e) Bancos de sangue.

f) Estabelecimentos que se dediquem exclusivamente à pesquiva e/ou ao ensino.

g) Posto de notificação da Sucam que não faça vacinação e/ou controle da malária.

h) Estabelecimentos criados em caráter de campanha e locais provisórios instalados em época de eleição.

\section{CONCEITUAÇÃO}

O IBGE atém-se aos "Conceitos e Definições" aplicados em saúde, oficializados pela Portaria MS n 30, de 05 de abril de 1977, que orienta o uso das nomenclaturas usadas em toda a área de saúde.

Cadernos de Saúde Pública, RJ, 7(3): 370-395, jul/set, 1991 
Posto de Saúde - é o estabelecimento destinado a prestar assistência sanitária a uma determinada população, de forma programada, utilizando técnicas simplificadas, pessoal de nivel médio ou elementar. As atividades típicas de um posto de saúde são a aplicação rotineira de vacinas, atendimento a gestantes, visita domiciliar etc.

Os Postos de Saúde recebem, também, as seguintes denominações: unidade elementar de saúde, posto municipal de saúde, posto de puericultura ou de assistência à gestante (sem assistência de médicos), postos ou unidades da Fundação de Serviços Especiais de Saúde Pública, minipostos e subpostos, subunidades sanitárias e posto sanitário.

Centro de Saúde - é o estabelecimento destinado a prestar assistência médico-sanitária, sem internação, a uma população determinada, contando com ambulatórios para assistência médica permanente, sempre que possível com médico. Como assistência médica generalista pemanente entende-se $o$ atendimento efetuado em estabelecimento, onde o médico comparece uma ou mais vezes por semana. Enquadram-se como centro de saúde os seguintes tipos de estabelecimentos: centro de saúde pública, centro sanitário, centro ou posto de assistência materno-infantil (com assistência de um médico), centro de medicina comunidade.

Clínicas ou Postos de Assistências Médicas (PAM) - é o estabelecimento de saúde destinado à assistência ambulatorial, em regime sem intenação. São assim classificados os ambulatórios ou postos de assistência médica do Inamps, ambulatórios ou postos médicos de centros sociais de sindicatos, do Sesi, do Senai, do SESC, do Senac, da LBA, do Funrural, do prelazias, de centros beneficentes ou de caixas assistenciais, clínica ou serviço ou centro ou unidade de qualquer especialidade médica ou odontológica, policlínica (sem internação).

Pronto Socorro - é o estabelecimento que funciona $24 \mathrm{~h}$ por dia, destinado a prestar assistência a pacientes com ou sem risco iminente de vida, cujo agravo à saúde necessite de atendimento imediato.

São classificados como Pronto Socorro:

- Pronto socorro (hospitais, clínicas, serviços, unidades ou centros).

- Pronto atendimento e/ou urgências médicas (hospitais, clínicas, serviços, unidades ou centros).

- Pronto atendimento e/ou urgências odontológicas (hospitais, clínicas, serviços, unidades ou centros). 
- Pronto clínica e/ou urgências médico-odontológicas.

Unidade Mista - é o estabelecimento de saúde com características de unidade sanitária, acrescido de leitos para internação de pacientes, basicamente em clínicas pediátricas, médico-cirúrgicas e de emergência. A distinção entre uma unidade mista e um hospital são as atividades médico-sanitárias, obrigatoriamente desenvolvidas nas unidades mistas.

Hospital - é o estabelecimento que tem por finalidade básica prestar assistência médica em regime de internação, por um periodo mínimo de $24 \mathrm{~h}$, possuindo leitos e instalações apropriadas. São classificados como hospital: casa de saúde, Santa Casa de Misericórdia, maternidade, casa de parto, manicômio, hospicio.

\section{INSTRUMENTO DE COLETA}

A obtenção das informações em 1980, se fez em um instrumento de coleta.

Já em 1987, foram utilizados dois instrumentos distintos; o $1^{\circ}$ composto de variáveis mais determinantes e pouco mutáveis, ano a ano, na constituição do estabelecimento, e que formam a base do cadastro (FAC - Formulário de Atualização Cadastral) e $\circ 2^{S}$ se estrutura de forma a atender à demanda dos tipos de serviço, separadamente para atendimento ambulatorial, de urgência e internação, acrescido ainda de indagaçōes generalizadas sobre o equipamento e empregos em saúde. As informações coletadas junto a estes estabelecimentos abrangem uma variedade importante de aspectos que, de um modo geral, permitem caracterizar desde a natureza juridica das entidades mantenedora, até o quadro de empregos lotado nos estabelecimentos; e as alterações observáveis periodicamente. Ou seja, permite classificar e categorizar setor institucionalizado de saúde do país sob uma gama variada de aspectos, constituindo-se, portanto, em uma das mais importantes fontes de dados para a pesquisa em saúde coletiva. Além desses instrumentos de coleta citados acima, existe o manual de instrução destinado ao informante, com conceitos e definições que possibilitem o preenchimento correto do questionário.

\section{SISTEMA DE COLETA DE DADOS}

O órgão central do IBGE envia os instrumentos de trabalho da pesquisa para as suas Delegacias (DEGE's) nas 
diversas Unidades da Federação. Por sua vez, cada DEGE, através das suas Agências de Coleta, os distribui para os estabelecimentos de saúde localizados na sua área de atuação.

O periodo de coleta é entre agosto e setembro, sendo que a remessa do material para o órgão central deve ser efetuado até o final de outubro.

\section{CRITICA, CODIFICAÇÃO E ENTRADA DE DADOS}

No órgão central, especificamente no Departamento de Estatísticas e Indicadores Sociais (DEISO), os questionários são criticados, codificados, revisados e encaminhados para digitação no órgão competente da Diretoria de Informática do IBGE. A seguir, são feitas as críticas de quantidade e de qualidade dos dados já então digitados em fita magnética.

\section{APURAÇÃO E SISTEMATIZAÇÃO}

Para efetuar a apuração dos resultados, são elaborados os gabaritos de espacejamento e a seleção de variáveis necessárias à apuração de cada tabela constante do plano tabular. Depois de feita a sistematização dos dados apurados, é efetuada a crítica de consistência e de compatibilização de todo o conjunto.

\section{DIVULGAÇÃO DOS RESULTADOS}

As tabelas aprovadas são encaminhadas, juntamente com o prefácio e formulário do respectivo ano, ao serviço responsável pela montagem da publicação e posteriormente enviadas ao Serviço Gráfico do IBGE, para impressão. Após o preparo dos volumes para divulgação pelo setor competente, os mesmos são oferecidos para o público em geral, através das próprias lojas de vendas de publicações do IBGE.

Até o presente momento foram divulgados, através da publicação anual Estatística da Saúde, os dados referentes aos anos de 1976 a 1987 . Em relação a 1988, os dados encontram-se em fase de processamento.

Além da publicação específica para a divulgação dos dados coletados, alguns resultados são encaminhados ao Centro Editorial do IBGE-GEDIT, para que sejam inseridos no Anuário Estatístico do Brasil. 
Cabe informar que as tabelas selecionadas para a divulgação não esgotam a possibilidade de tabulação dos resultados da pesquisa.

\section{PRINCIPAIS VARIÁVEIS PESQUISADAS}

As variáveis consideradas relevantes ao escopo do estudo

\section{a) Relativas à capacidade Física Instalada}

- Estabelecimento:

Corresponde à unidade de prestação, englobando desde um centro de saúde a um complexo hospitalar.

- Leitos:

Corresponde a uma unidade física destinada à internação de um paciente.

b) Relativas a Emprego

- Emprego de Saúde:

Corresponde ao total de empregos das categorias típicas do setor e são divididas por turnos (integral e parcial).

As dezoito categorias típicas estão classificadas, segundo o grau de escolaridade em:

- Nivel superior:

Assistente social, bioquímico, enfermeiro, farmacêutico, fisioterapeuta, fonoaudiólogo, médico, nutricionista, odontólogo, psicólogo, sanitarista, terapeuta ocupacional.

- Nivel Médio/Técnico:

Técnico ou auxiliar de enfermagem

Técnico auxiliar de Fisioterapia

Técnico auxiliar de Laboratório

Técnico auxiliar de Nutriçāo

Técnico auxiliar de Radiologia

Técnico Auxiliar de Saneamento

Auxiliar de Farmácia

Auxiliar de Odontologia

Protético

Inspetor Sanitário

Visitador Sanitário

- Nivel Elementar.

Atendente ou auxiliar de serviços diversos

Agente de Saneamento

Agente de Saúde Pública

Parteira 
Para cada uma destas variáveis, correspondem como variáveis dependentes:

A natureza da entidade mantenedora do estabelecimento:

$\begin{aligned} & \text { Público } \text { - Federal } \\ & \text { - Estadual } \\ & \text { - Municipal }\end{aligned}$

Privado - Lucrativo
- Não-lucrativo

Existência de Convênio - Inamps

- Inamps/Empresa

Regime de Atendimento - Com internação

- Sem internação

Observação: A distinção da natureza lucrativa ou não-lucrativa dos estabelecimentos privados e de corte jurídico-formal não corresponde, necessariamente, à realidade da dinâmica econômica dos mesmos.

Modificação na Pesquisa AMS, de 1980/1987, na Capacidade Instalada:

- Estabelecimentos:

Não houve alteração nos conceitos, mas sim na forma de captar informação.

- Tipo de Estabelecimento: (Posto de Saúde, Centro de Saúde etc).

1980 - Inexistia esse quesito, era o IBGE que classificava os estabelecimentos.

1987 - No formulário FAC, passou a existir.

- Categoria: (GeralEspecializado)

1980 - Somente as citadas acima.

1987 - Incluía, além das especificadas acima, o quesito "NÃO ESPECIALIZADO"

\section{Convênios e Contratos:}

1980 - Era respondido através de apenas seis quesitos.

1987 - Em relação aos estabelecimentos em convênio com o Inamps, ficou mais especificado, totalizando treze quesitos. Quanto aos outros estabelecimentos, contavam com cinco quesitos. 
- Empregos de Saúde

A principal modificação introduzida nas questões relacionadas a empregos, entre a AMS-80 e o questionário AMS-87, dizem respeito a:

a) Foi introduzido um bloco sobre disponibilidade de pessoal no estabelecimento por dias da semana, o que permitiria agregar informações sobre jomada de trabalho efetiva, que são de extrema importância no mapeamento da capacidade produtiva real do estabelecimento.

b) Foram agregadas novas categorias profissionais no elenco já existente, destacando-se as seguintes: bioquímico, fisioterapeuta, fonoaudiólogo, terapeuta ocupacional, técnico ou auxiliar de fisioterapia, técnico ou auxiliar de nutrição, auxiliar de farmácia, auxiliar de odontologia e protético.

Todas essas novas informações, com os cruzamentos permitidos pelo questionário, vão agregar inúmeras possibilidades adicionais de análise no campo do emprego em saúde no Brasil. Convém ressaltar que, na AMS-85, houve introdução de um terceiro questionário, correspondente aos dados financeiros do estabelecimento, onde se destacavam as despesas e as receitas.

\section{ALGUNS INDICADORES DA PESQUISA AMS}

É inquestionável a importância das informações da pesquisa AMS para subsidiar os órgãos públicos na área de saúde.

Nesse sentido, a título de ilustração, destacamos alguns indicadores sobre capacidade instalada no Brasil em 1980 e 1987.

Para avaliarmos o desempenho do setor de prestação de serviços de saúde no período recente, no tocante ao crescimento da capacidade instalada e do emprego, faz-se necessário remeter a pelo menos duas questões que contribuem para explicar uma série de tendências observadas e características do setor.

A primeira delas diz respeito às políticas de saúde implementadas pelo Estado Brasileiro no Pós-1970, que favoreceram, por um lado, a consolidação de um vasto complexo hospitalar de natureza empresarial-lucrativa no país e, por outro, relegaram o conjunto das práticas institucionais organizadas para enfrentar as demandas sanitárias de expressão mais coletivas, a saúde pública. 
A segunda delas, de ordem mais conjuntural, diz respeito à crise econômica dos anos 80 , que teve repercussões sobre os padrões de distribuição setorial da capacidade instalada e do emprego, explicando uma série de tendências manifestas no periodo.

Diante destas questões, observamos, nas tabelas em anexo, o predomínio de segmento hospitalar dos serviços de saúde, no que diz respeito à disponibilidade de recursos $\mathrm{e}$ à absorção de postos de trabalho, fenômeno que vem prevalecendo até os dias de hoje.

A pesquisa da AMS mostra que, em 1987, os 5.359 estabelecimentos com regime de internação existente no país, no setor privado, demandaram nada menos que $36,8 \%$ do total de empregos existente nos 32.450 estabelecimentos. Este fato se observa, também, em 1980, quando o crescimento desses estabelecimentos foi de $9,5 \%$, havendo um decréscimo $(-0,1)$ nos empregos deste setor. Mesmo assim, o setor privado mantém a hegemonia neste segmento de prestação de serviço.

$\mathrm{Na}$ última década, a capacidade instalada em leitos hospitalares evoluiu 4,9\%, notabilizando-se, sob este aspecto, o crescimento na rede privada que, no período, chega a aumentar 30.000 leitos, em detrimento do setor público, que apresentou um decréscimo de $\mathbf{- 3 . 7 \%}$. De qualquer forma, a pesquisa revela uma das faces do formato da intervenção estatal em saúde no periodo, vale dizer, sua natureza privatizante.

Sabe-se que uma parte não-desprezível destes leitos encontra-se em estabelecimentos de grande porte, mantidos por fundações particulares, instituiçōes filantrópicas e beneficentes, estabelecimentos que detêm em realidade uma dinâmica econômica de corte empresarial.

\section{TENDENCIAS DA INFRA-ESTRUTURA DOS SERVIÇOS DE SAÚDE NO BRASIL, 1980/1987}

\section{Estabelecimentos}

Observamos na tabela I que, no período, o setor público detinha maior parcela de estabelecimentos, e que esses se concentravam no regime sem internação. De forma inversa, o setor privado detinha a maioria absoluta na área hospitalar (com internação).

Entre 1980 e 1987, conforme se pode ver na tabela I, o segmento ambulatorial apresentou um dinamismo mais 
acentuado que o hospitalar, apresentando elevadas taxas de crescimento. Neste segmento de prestação de serviço de saúde, conforme se sabe amplamente, há hegemonia do setor público, e isto já constitui uma tradição.

\section{TABELA I}

Evolução da Capacidade Instalada

nos Serviços de Saúde. Brasil - 1980/87

\begin{tabular}{|c|c|c|c|c|c|}
\hline \multirow{2}{*}{ Discriminação } & \multirow{2}{*}{ Total } & \multicolumn{2}{|r|}{ Públicos } & \multicolumn{2}{|c|}{ Privados } \\
\hline & & Com Internaçăo & Sem Internaçåo & Com Internaçăo & Sem Internaçå̉o \\
\hline \multicolumn{6}{|l|}{ Estabelecimentos } \\
\hline 1980 & 18.489 & 1.217 & 8.828 & 4.893 & 3.551 \\
\hline 1987 & 32.450 & 1.703 & 18.471 & 5.359 & 6.917 \\
\hline Incremento bruto (\%) & 75,5 & 39,9 & 109,2 & 9,5 & 94,8 \\
\hline \multicolumn{6}{|l|}{ Leitos } \\
\hline 1980 & 495.633 & 120.275 & - & 375.358 & - \\
\hline 1987 & 519.698 & 115.842 & - & 403.856 & - \\
\hline Incremento bruto (\%) & 4,9 & $-3,7$ & - & 7,6 & - \\
\hline \multicolumn{6}{|l|}{ Empregos } \\
\hline 1980 & 573.629 & 144.014 & 121.942 & 271.911 & 35.762 \\
\hline 1987 & 742.559 & 216.536 & 194.783 & 271.537 & 59.703 \\
\hline Incremento bruto (\%) & 29,4 & 50,4 & 59,7 & $-0,1$ & 66,9 \\
\hline
\end{tabular}

Fonte: IBGE, AMS-80 a AMS-87.

Em relação aos setores público e privado, os estabelecimentos se apresentam da seguinte maneira:

- No setor público, há predominância nas esferas do estado e municípios; observa-se este fenômeno nas cinco regiões.

- No setor privado, em 1980, os estabelecimentos com fins lucrativos apresentam os maiores percentuais, exceto na região Nordeste.

Já no ano de 1987, nas regiōes Norte, Sudeste e Centro-Oeste, permanece a situação e, nos demais setores, há predominância de estabelecimentos sem fins lucrativos; e, se compararmos com o ano de 1980 , observaremos que houve um decréscimo em sua participação. 
Conforme já demonstramos, a AMS informava, para 1987, a existência de 32.450 estabelecimentos no setor formal da prestação de serviços de saúde no Brasil. Destes, 25.388 eram caracterizados como estabelecimentos sem regime de internação, ou seja, Postos e Centro de Saúde, Policlínicas e Postos de Assistência Médica.

Somente a região Nordeste possui $16,6 \%$ dos postos de saúde, $68 \%$ das unidades mistas e $45,5 \%$ dos hospitais exis- 
tentes no Brasil, isto é $39,0 \%$ da capacidade instalada no setor público no segmento de atendimento (Quadro I).

\section{QUADRO I}

Estabelecimentos Públicos por Espécie, segundo as Grandes Regiöes

\begin{tabular}{lcccccc}
\hline \multicolumn{7}{c}{ Estabelecimentos Públicos } \\
Grandes & Postos de & Centro & Clfíca ou & Pronto & Unidade & Hospital \\
Regiöes & Saúde & Saúde & PAM & Socorro & Mista & \\
\hline Brasil Abs. & 4.950 & 11.553 & 1.817 & 151 & 554 & 1.149 \\
& 100,0 & 100,0 & 100,0 & 100,0 & 100,0 & 100,0 \\
Norte & 1.126 & 290 & 24 & 2 & 132 & 69 \\
& 22,7 & 2,5 & 1,3 & 1,3 & 23,8 & 6,0 \\
Nordeste & 2.803 & 3.121 & 383 & 11 & 377 & 526 \\
& 56,6 & 27,0 & 21,0 & 7,3 & 68,0 & 45,8 \\
Sudeste & 619 & 4.452 & 913 & 128 & 26 & 318 \\
& 12,5 & 38,5 & 50,2 & 84,7 & 4,6 & 27,7 \\
Sul & 198 & 2.845 & 455 & 6 & 1 & 131 \\
& 0,5 & 24,6 & 25,0 & 3,9 & 0,1 & 11,4 \\
C. Oeste & 204 & 845 & 42 & 4 & 19 & 105 \\
& 7,7 & 7,4 & 2,5 & 2,8 & 3,5 & 9,1 \\
\hline
\end{tabular}

Fonte: IBGE, AMS - 87.

Já a região Sudeste detém a segunda colocação, com $50 \%$ das clínicas e postos de assistência médica e $84 \%$ dos pronto-socorros do país.

Por outro lado, não podemos esquecer que, desses estabelecimentos ambulatoriais, grande parte é de pequeno porte, destinada à prestação de cuidados básicos simplificados.

\section{Leitos}

A rede hospitalar brasileira era constituída, na década de 80 , em sua expressiva maioria, pelo setor privado.

Observamos na tabela $\Pi I$ que, enquanto a rede privada, em quase uma década, aumentava sua capacidade instalada em leitos, os hospitais da rede pública tiveram esta capacidade estagnada na casa de 120 mil leitos, em média, 25,0\% do total. Em quase todas as unidades da federação houve 
decréscimo de leitos, exceto nas regiōes Norte e Nordeste, acentuando o maior decréscimo na região Sudeste. Curioso é que observamos esta tendência, também, no setor privado.

Um indicador da importância assumida pela iniciativa privada empresarial na área da assistência médica ambulatorial é o aumento dos contratos de prestação de serviços celebrados com as empresas de medicina de grupo e com cooperativas médicas, na década de 1980. A bem da verdade, estas condições de atuação dos subsetores públicos e privados na área de assistência à saúde já se encontravam definidas desde a reforma administrativa de 1967 (Possas, 1981).

Estabelecia-se, desde então, no mesmo texto da lei, que o setor público só deveria intervir diretamente naqueles casos que não interessam ao setor privado, seja pelo alto custo operacional envolvido, sejam pelas dificuldades técnico-operativas encontradas ou ainda pela pequena rentabilidade do investimento.

\section{Empregos}

A expansão dos empregos no setor saúde está vinculada ao crescimento das atividades terciárias, verificado no Brasil mais intensamente nos anos 70. Nem mesmo com o aliviamento da crise nos anos 80 , observou-se uma redução acentuada no crescimento da oferta de empregos no setor saúde. Ao contrário, enquanto a População Economicamente Ativa (PEA) passou a crescer, na primeira metade da década, $3,8 \%$ ao ano, o setor saúde manteve um crescimento anual de $6,41 \%$.

Segundo os censos de $70 / 80$, cerca de $50 \%$ do total de pessoas ocupadas no país inseriam-se em atividades terciárias, e o setor saúde detinha mais de um milhão de postos de trabalho, o que representava praticamente $1 / 4$ do contingente de ocupados nas atividades sociais, significando $5,0 \%$ dos empregos no país.

A maioria absoluta dos empregados de saúde é remunerada direta ou indiretamente pelos cofres públicos, independente de estarem localizados em instituiçōes públicas ou privadas, o que fez com que a dinâmica do emprego setorial fosse determinada, em última análise, pelas decisões governamentais.

Em 1987, 55,4\% dos empregados de saúde eram mantidos diretamente pelo setor público, totalizando 411.319 empregos de profissionais de saúde. Fora o financiamento 
das despesas de custeio da iniciativa privada, que é feito através de inserçōes fiscais.

\section{TABELA III}

Leitos para Internação em 31 de Dezembro, Existentes nos Estabelecimentos de Saúde e Taxa Média Geométrica de Crescimento Anual, por Tipo de Atendimento,

Segundo as Grandes Regiôes e Unidades da Federação - 1980 - 87

\begin{tabular}{|c|c|c|c|c|c|c|}
\hline \multirow{3}{*}{$\begin{array}{c}\text { Grandes Regiões } \\
\text { e } \\
\text { Unidades da Federação }\end{array}$} & \multicolumn{6}{|c|}{ Estabelecimentos } \\
\hline & \multicolumn{3}{|c|}{ Público } & \multicolumn{3}{|c|}{ Privado } \\
\hline & 1980 & 1987 & $\begin{array}{c}\text { Taxa Média } \\
\text { Geométrica } \\
\text { de } \\
\text { Crescimento } \\
\text { Anual }\end{array}$ & 1980 & 1987 & $\begin{array}{c}\text { Taxa Média } \\
\text { Geométrica de } \\
\text { Crescimento } \\
\text { Anual }\end{array}$ \\
\hline BRASIL & 122.722 & 115.842 & $-0,8$ & 386.382 & 403.856 & 0,6 \\
\hline Regiäo Norte & 6.135 & 7.828 & 3,5 & 8.653 & 9.674 & 1,6 \\
\hline Rondônia & 670 & 1.437 & 11,9 & 798 & 1.485 & 9,2 \\
\hline Acre & 636 & 838 & 4,0 & 393 & 510 & 3,8 \\
\hline Amazonas & 1.840 & 2.129 & 2,1 & 1.470 & 1.010 & $-5,2$ \\
\hline Roraima & 245 & 409 & 7,6 & 114 & 61 & $-8,5$ \\
\hline Para & 2.462 & 2.640 & 1,0 & 5.673 & 6.392 & 1,7 \\
\hline Amapá & 282 & 375 & 4,2 & 205 & 216 & $-0,7$ \\
\hline Regiắo Nordeste & 29.550 & 33.832 & 2,0 & 58.285 & 72.685 & 3,2 \\
\hline Maranhão & 1.671 & 3.059 & 9,0 & 4.177 & 7.911 & 9,6 \\
\hline Piauf & 2.483 & 2.657 & 1,0 & 1.742 & 2.369 & 4,5 \\
\hline Ceara & 3.882 & 4.277 & 1,4 & 12.986 & 14.502 & 1,6 \\
\hline Rio Grande do Norte & 2.123 & 2.663 & 3,3 & 3.397 & 3807 & 1,6 \\
\hline Parafba & 3.237 & 3.24 & 0,0 & 6.137 & 7.879 & 3,6 \\
\hline Pernambuco & 8.223 & 8.286 & 0,1 & 11.067 & 14.112 & 3,5 \\
\hline Alagoas & 1.890 & 2.290 & 2,8 & 4.168 & 5.008 & 2,7 \\
\hline Sergipe & 735 & 1.012 & 4,7 & 2.409 & 2.686 & 1,6 \\
\hline Bahia & 5.306 & 6.344 & 2,6 & 12.202 & 14.411 & 2,4 \\
\hline Regiåo Sudeste & 63.408 & 50.608 & $-3,2$ & 214.390 & 212,482 & $\infty, 1$ \\
\hline Minas Gerais & 11.645 & 7.988 & $-5,2$ & 46.992 & 49.452 & 0,7 \\
\hline Espfrito Santo & 2.439 & 1.639 & $-5,5$ & 4.904 & 5.915 & 2,7 \\
\hline Rio de Janeiro & 24.875 & 19.771 & $-3,2$ & 51.107 & 48.522 & $-0,7$ \\
\hline São Paulo & 24.449 & 21.210 & $-2,0$ & 111.387 & 108.593 & $\infty, 4$ \\
\hline Regiāo Sul & 16.598 & 15.010 & $-1,4$ & 79.941 & 78.795 & $-0,2$ \\
\hline Paraná & 4.707 & 4.137 & $-1,8$ & 34.008 & 35.051 & $-0,4$ \\
\hline Santa Catarina & 4.356 & 4.179 & $=0,6$ & 12.649 & 13.151 & $-0,6$ \\
\hline Rio Grande do Sul & 7.535 & 6.694 & $-1,7$ & 33.284 & 30.593 & $-1,2$ \\
\hline Regiăo Centro-Oeste & 7031 & 8564 & 2,8 & 25.113 & 30.220 & 2,7 \\
\hline Mato Grosso do Sul & 528 & 611 & 2,1 & 4.995 & 6,022 & 2,7 \\
\hline Mato Grosso & 690 & 533 & $-3,6$ & 4.002 & 5.304 & 4,1 \\
\hline Goiás & 3.026 & 3.739 & 3,1 & 14.959 & 17.796 & 2,5 \\
\hline Distrito Federal & 2.787 & 3.681 & 4,1 & 1.157 & 1.108 & $-0,6$ \\
\hline
\end{tabular}

Fonte: IBGE, AMS-80 e AMS-87. 
PESQUISA

$$
\begin{aligned}
& \text { QUADRO II } \\
& \text { Situação do FTS no Brasil }(1970-1980)
\end{aligned}
$$

\begin{tabular}{|c|c|c|}
\hline Especificaçăo & 1970 & 1980 \\
\hline Total & 622.004 & 1.233 .008 \\
\hline \multicolumn{3}{|l|}{ Com capacitação na ârea de saúde } \\
\hline Profissionais de Safde & 306.730 & 614.686 \\
\hline \multicolumn{3}{|l|}{ Sem capacitaçåo } \\
\hline N\&o-profissionais de Saf́de & 315.274 & 618.322 \\
\hline Profissionais no setor de saude & 560.272 & 1.170 .785 \\
\hline \multicolumn{3}{|l|}{ Formados na area, mas atuando em outra } \\
\hline Profissionais em outro setor & 61.732 & 62.223 \\
\hline Profissionais de saúde em relaçăo $\infty$ m PEA & $1,94 \%$ & $2,67 \%$ \\
\hline
\end{tabular}

OBS: Pessoas ocupadas sem remuneração e profissionais de saúde à procura de emprego estáo inchufdas no total.

Em suma, comportamento do emprego em saúde vem obedecendo, em linhas gerais, as mesmas leis que regulam o crescimento das atividades e dos empregos governamentais, particularmente na área social.

ALGUMAS TENDENCIAS - PERIODO DE 1980/1987

Setor Público x Privado

Durante o período $80-87$, como já vimos, empregos em saúde cresceram de forma mais acelerada no setor público.

Dessa forma assistimos, na década de 1980, por conta da expansão do público, a uma inversão do perfil da distribuição institucional dos empregos de saúde. O setor privado, que detinha a grande parte dos empregos em 1980, perde esta posição. Em 1987, o setor público passava a deter a maioria dos postos de trabalho.

\section{Divisão Setorial do Trabalho}

As recentes mudanças sócio-político-econômicas ocorridas nestas últimas décadas têm alterado de forma decisiva 
o comportamento do mercado de trabalho, das diversas categorias profissionais, e o conjunto de trabalhadores de saúde no Brasil.

\section{GRÁFICO I}

\section{Empregos de Saúde} Entidade Mantenedora 1980-1987

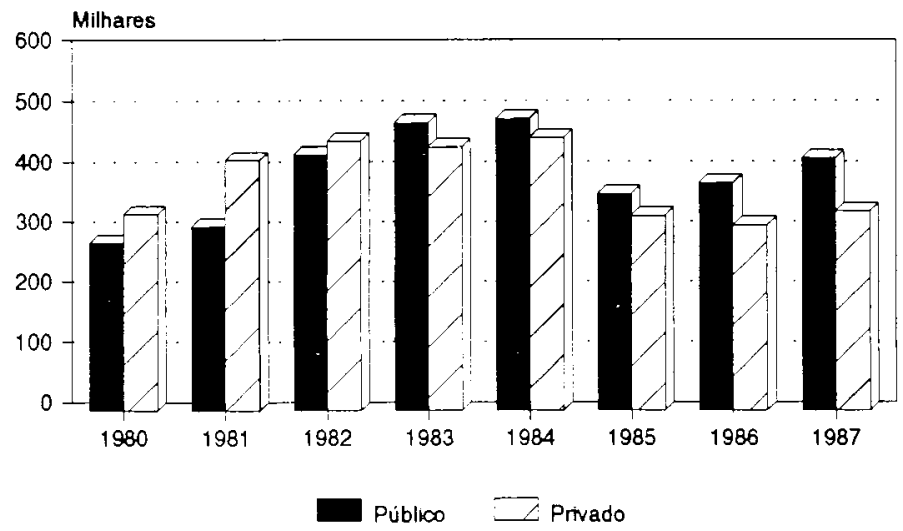

Fonte $\cdot$ IGGE - AMSBBO a AMSI87

Contudo, a prestação de serviços de saúde ainda guarda características do passado, onde havia as presenças centrais do médico (mão-de-obra qualificada) e do atendente (mão-de-obra de baixa qualificação).

Em 1987, através da tabela IV, podemos demonstrar que, dos 742.559 empregos de saúde existentes, 206.372 eram de médicos e 209.087 de atendentes, o que representava mais de $55,9 \%$ da Força de Trabalho em Saúde, e é o setor privado o que mais caracteriza esta situação.

Ressalte-se que estamos falando em postos de trabalho e, neste caso, a vocação do mercado de trabalho em saúde é a absorção (para um médico) de dois a três postos de trabalho; diferentemente do comportamento dos atendentes quando, via de regra, a cada posto de trabalho corresponde um profissional; neste sentido, o hiato entre a mão-de-obra mais qualificada e a menos qualificada é ainda mais profunda. 


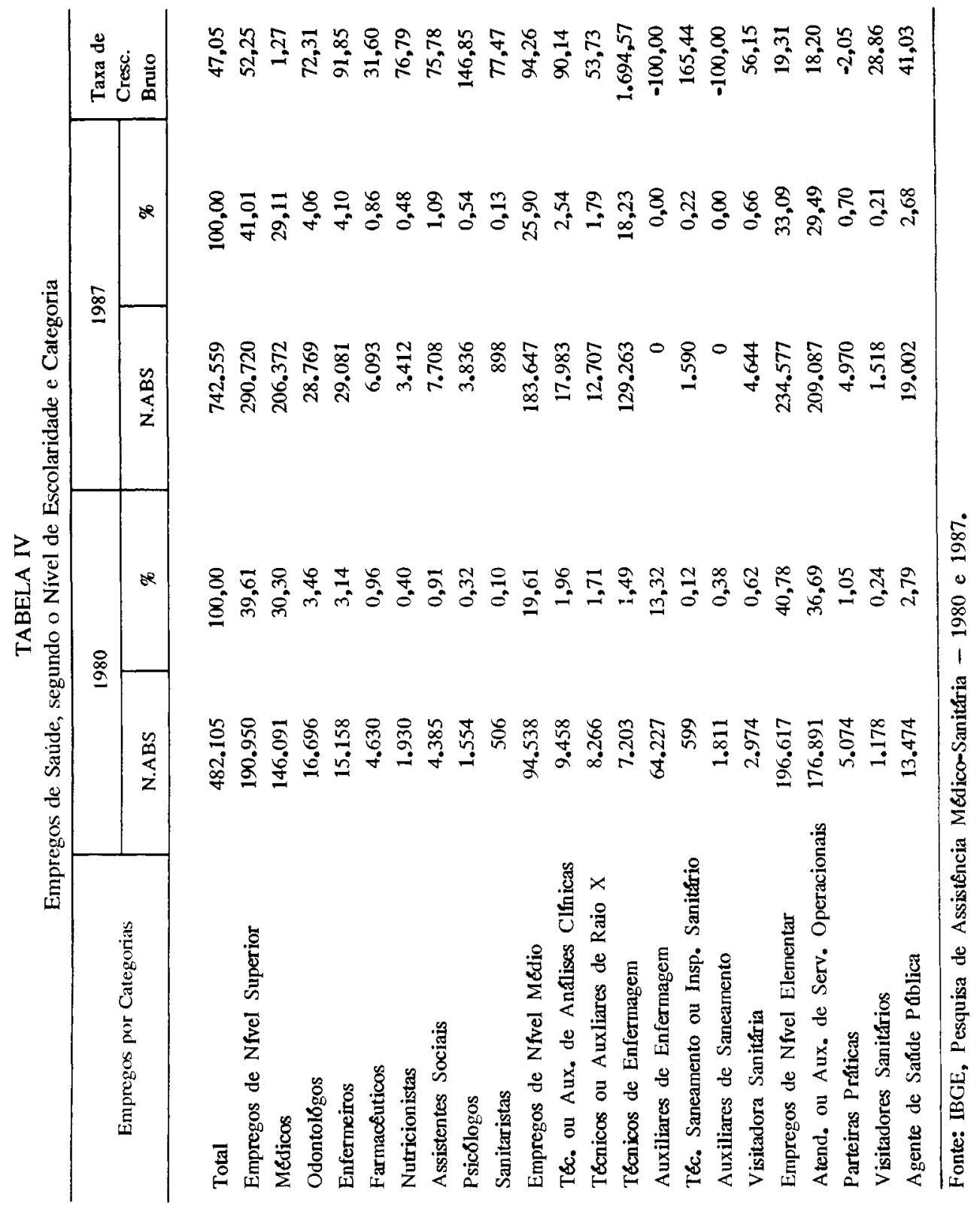




\section{Escolaridade}

Uma das tendências mais marcantes do mercado de trabalho em saúde é o aumento expressivo de profissionais de nível superior na composição de FTS, alcançado nos anos de 85/87.

Uma das possíveis explicações para esta inversão da composição foi o processo eleitoral ocorrido em 1986, pois observamos que o aumento maior ocorreu no setor público.

Paralelo a isto, ocorreu em todo o pais o processo de ambulatorização, com as ações integradas de saúde (AIS), expandindo os empregos públicos nos estabelecimentos sem internação.

Ao particularizarmos a análise por setor (público e privado), certificamos que o setor público tende a absorver maior parcela do mercado de trabalho em saúde. Mais, curiosamente, é o setor privado que notamos a maior racionalização na absorção de profissionais mais qualificados, seja de nível médio ou superior, como fica evidenciado nas tabelas em anexo.

\section{GRÁFICO II}

Empregos de Saúde, por Classificação da Entidade Mantenedora, Segundo o Nível de Escolaridade

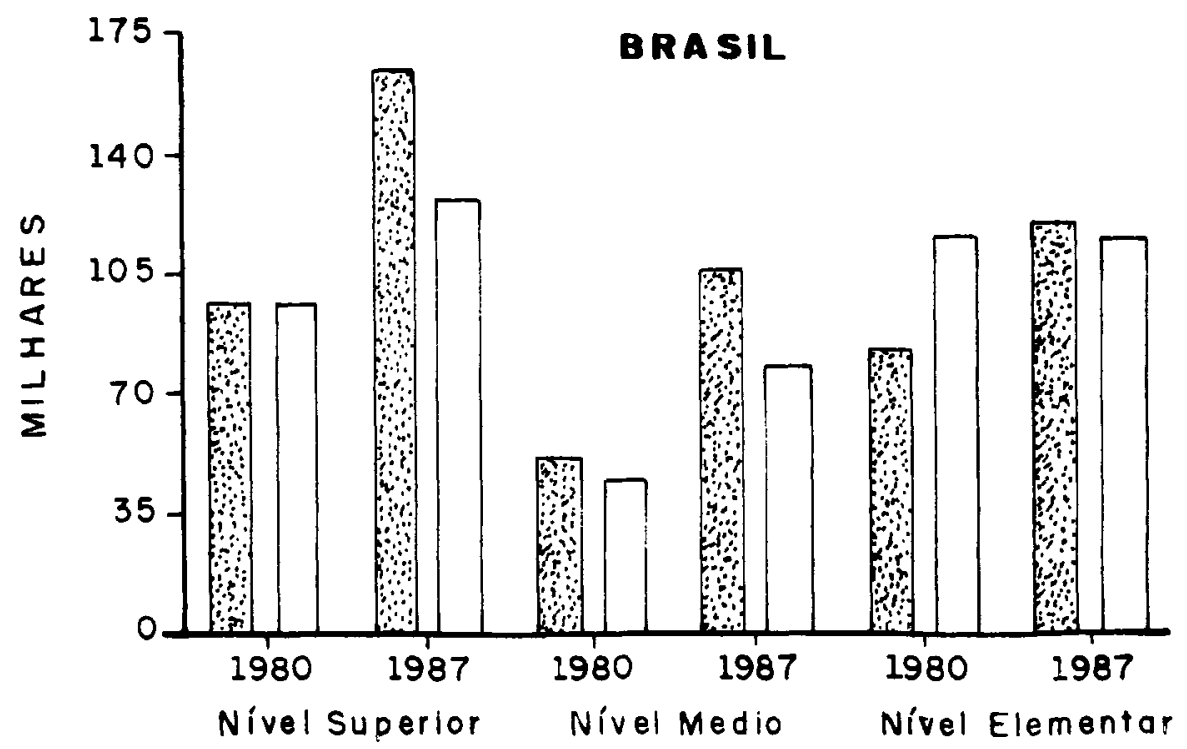

Wa Público Privado 


\section{Distribuição Espacial dos Empregos}

As desigualdades espaciais dos empregos em saúde podem, também, ser constatadas através dos percentuais da capital e o resto dos municípios que retratam a situação da região Sudeste; a rede pública concentrou grande parte dos profissionais de saúde da capital nos anos de 80 e 87 .

Notamos na tabela $V$ que, nos anos 80 , a capital dos estados concentrava maior número de empregos, em quase todas as categorias.

O Estado do Espírito Santo foi o que apresentou um acréscimo mais acentuado de captação de médicos, no setor privado.

\section{DISTRIBUIÇÃO REGIONAL DA CAPACIDADE INSTALADA}

Embora seja um reflexo da concentração das políticas sociais do governo, as regiões Sudeste e Nordeste seguem sendo as que possuem mais elevadas taxas de capacidade instalada.

A tabela VI evidencia que a região Sudeste concentrava $36,6 \%$ dos estabelecimentos de Saúde, $50 \%$ dos leitos e $53,7 \%$ dos empregados, em 1987. Esta concentração excessiva de profissionais para uma relativamente menor de estabelecimentos deveu-se às distinções regionais quanto à natureza dos estabelecimentos.

O Sudeste é caracterizado pela presença de grandes hospitais, muitos dos quais são centros de referência nacional e boa parte deles, detendo alto nível de complexidade, incorporando grande contingente de profissionais de saúde. Além disso, é agora a região de maior renda nacional, o que traz maior oferta de serviços médicos e exames complementares privados.

$O$ ideal seria que, guardados os parâmetros técnicos relacionados a cada tipo de padrão sócio-epidemiológico, houvesse uma homogeneidade entre a distribuição da população e a distribuição da capacidade instalada a nível nacional, em moldes mais equitativos. A distribuição espacial da capacidade instalada fornece um quadro que mostra como ainda é precária a estrutura de atendimento aos problemas de saúde de regiões como o norte e nordeste. A esta concentração geográfica soma-se outra, ainda mais nefasta aos principios de universalização e equipe, que é a concentração nas grandes áreas metropolitanas, nos municípios das capitais.

Cadernos de Saúde Pública, RJ, 7(3): 370-395, jul/set, 1991 


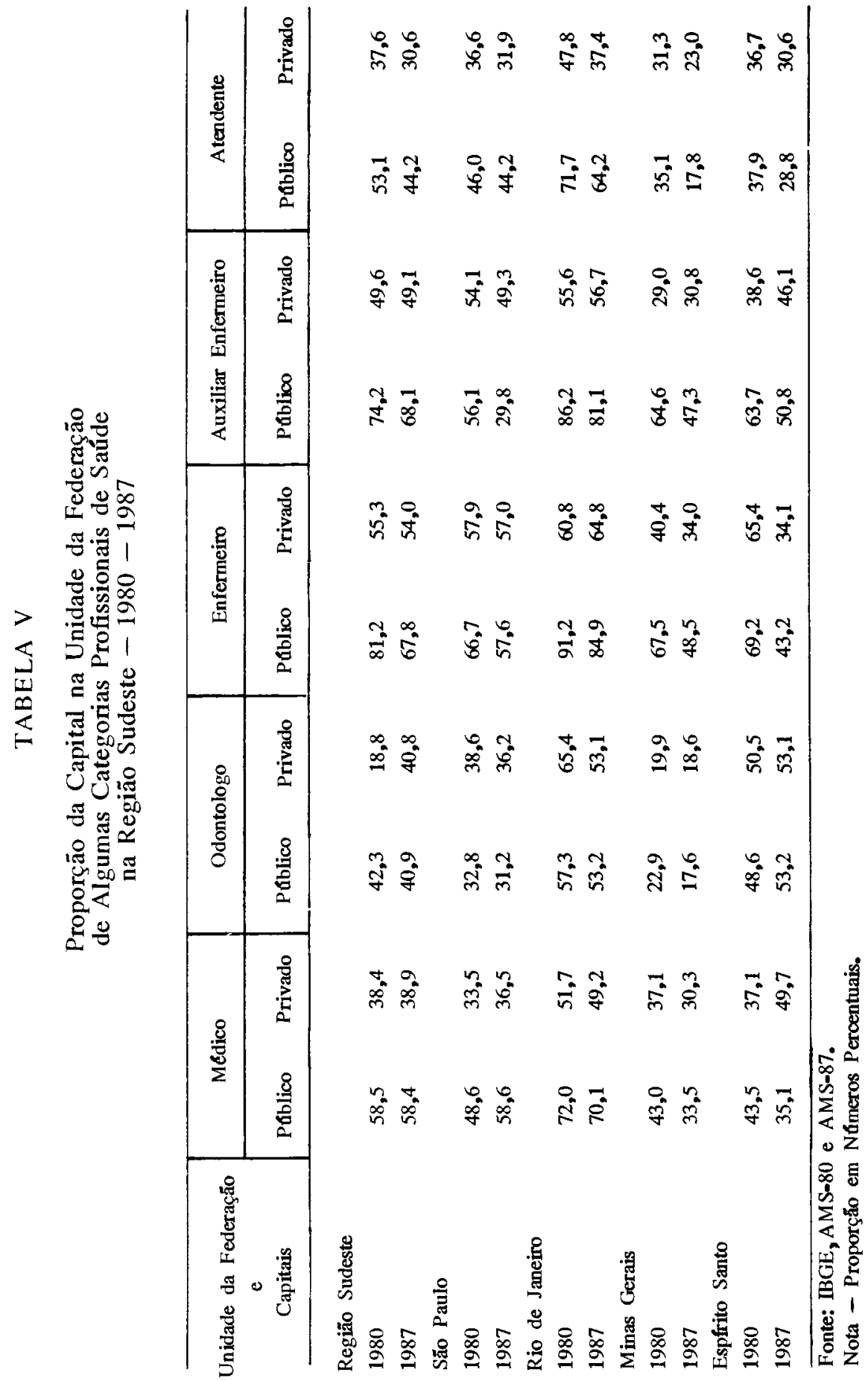


PESQUISA

TABELA VI

Distribuição da População e da Capacidade Instalada

\begin{tabular}{|c|c|c|c|c|c|c|c|c|}
\hline \multirow{3}{*}{$\begin{array}{c}\text { Brasil } \\
\text { e } \\
\text { Regiöes }\end{array}$} & \multicolumn{2}{|c|}{ População } & \multicolumn{6}{|c|}{ Capacidade Instalada } \\
\hline & \multirow{2}{*}{$\frac{\text { Residente }}{1980}$} & \multirow{2}{*}{$\frac{\text { Estimada }}{1987}$} & \multicolumn{2}{|c|}{ Estabelecimentos } & \multicolumn{2}{|c|}{ Leitos } & \multicolumn{2}{|c|}{ Empregos } \\
\hline & & & 1980 & 1987 & 1980 & 1987 & 1980 & 1987 \\
\hline Brasil & 100,0 & 100,0 & 100,0 & 100,0 & 100,0 & 100,0 & 100,0 & 100,0 \\
\hline Regiăo Norte & 4,9 & 5,8 & 4,2 & 6,4 & 2,9 & 3,4 & 3,4 & 3,8 \\
\hline Regiăo Nordeste & 29,3 & 28,6 & 29,4 & 30,7 & 17,2 & 20,5 & 19,9 & 22,0 \\
\hline Regiăo Sudeste & 43,4 & 43,6 & 44,6 & 36,6 & 54,5 & 50,6 & 54,8 & 53,7 \\
\hline Regiăo Sul & 16,0 & 15,2 & 17,4 & 19,7 & 18,9 & 18,0 & 16,4 & 13,9 \\
\hline Regif̊o Centro-Oeste & 6,4 & 6,8 & 6,0 & 6,6 & 6,5 & 7,5 & 5,5 & 6,6 \\
\hline
\end{tabular}

Fonte: CD - 80 - AMS-87, IBGE

\section{CONCLUSÃO}

$\mathrm{Na}$ medida em que buscamos particularizar alguns aspectos do crescimento do setor saúde no período, levando em conta o comportamento de cada uma das modalidades institucionais que o constituem, revelam-se importantes peculiaridades.

Podemos constatar que, em linhas gerais, as modalidades de prestadores mantidas pelo setor público apresentaram, via de regra, maiores taxas de crescimento de seus efeitos de capacidade instalada (estabelecimentos, leitos e empregos) que as mantidas pelo setor privado.

Observamos que os estabelecimentos privados de regime ambulatorial apresentaram, no período, um comportamento bastante semelhante ao observado para o setor público.

Em relação à dinâmica da rede de estabelecimentos com insternação, notamos que o ritmo de geração de empregos de saúde neste segmento, no setor público, situou-se, no período, em niveis mais altos que o setor privado, no que se refere a taxas de incorporação de novos leitos para internação. Enquanto o setor público teve seus niveis estagnados, a rede de estabelecimentos hospitalares lucrativos teve um acréscimo razoável. 
As tabelas referentes a capacidade instalada, em sua análise, confirma aquelas tendências que vínhamos comentando e permite aproximaçāo de certa forma mais imediata em relação aos impactos de conjunturas reais mais especificas sobre o comportamento das diversas formas de organização da prestação de serviços. Assim, as três principais tendências, no periodo 1980/1987, são:
A) A tendência ao maior crescimento do segmento "sem internação".
B) Tendência de maior crescimento da capacidade instalada nos estabelecimentos públicos.
C) Tendências ao acentuado dinamismo na incorporação de empregos, bem como na instalação de novos estabele- privada. cimentos na rede ambulatorial, mantidos pela iniciativa

\section{COMENTÁRIO FINAL}

Embora a pesquisa AMS seja a fonte de dados mais completa sobre a capacidade instalada, a avaliação de seu uso precisa ser enquadrada no contexto do sistema nacional de informações para saúde.

Faz-se necessária esta discussão devido às variações de diferentes momentos históricos vivenciados no país. Nesse particular, não há dúvida de que o panorama mudou muito desde o tempo em que foi idealizada a AMS-1985 e os dias de hoje.

É preciso rever cuidadosamente o sistema de informação como um todo, no IBGE. E, nessa revisão geral, torna-se imprescindivel avaliar a relação produtor-usuário, para que o usuário aprenda a fazer uma explicitação das suas reais necessidades e uma utilização mais adequada das informações geradas.

Nessa reavaliação, deveriam ser discutidos não somente o conteúdo, mas também a agilização do acesso às informações. Um dos grandes bloqueios, que persiste e que estorva o desenvolvimento científico e a utilização de dados no processo de planejamento, é a morosidade da divulgação e a dificuldade no acesso às informações.

Esse bloqueio precisa ser analisado e sanado, inclusive à luz dos desenvolvimentos na área de informática. 
This paper presents and discusses the role of the research "Medical and Sanitary Care" (Assistência médico-sanitária-AMS) developed by the IBGE (Brazilian Institute of Geography and Statistics) in the context of the Brazilian Health System Reform process. It points out the importance of stablishing a greater interaction between the IBGE and the user of this institution's information system in such a way that users' needs can be more clearly expressed in order to achieve a more productive use of the available information. Finally, the Author suggests that there should be some improvements in the diffusion of these researches and in the access to IBGE's data bases, for these issues constitute two major barriers for the health planning process.

\section{REFERENCIAS BIBLIOGRÁFICAS}

INSTITUTO BRASILEIRO DE GEOGRAFIA E ESTATISTICA, Estatisticas de Saúde, Assistência Médico-Sanitária - IBGE, Rio de Janeiro, 1987.

MÉDICI, A.C., AGUIAR, M.A. - Para Entender o Mercado de Trabalho - Universidade Santa Úrsula. IBASE, Rio de Janeiro, 1986.

OLIVEIRA, E.S. A História das Estatisticas de Saúde, IBGE (documento mimeografado), 1986.

POSSAS, C.A. - Saúde e Trabalho: A Crise da Previdencia Social, RJ, Editora Graal, 1981. 


\section{Anexo}

\section{Classificação da Entidade Mantenedora}

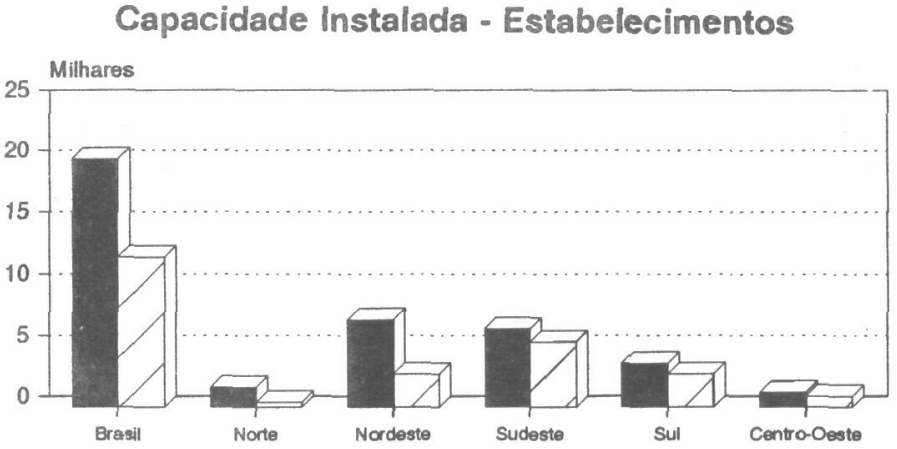

Público $\square$ Privado

Capacidade Instalada - Leitos
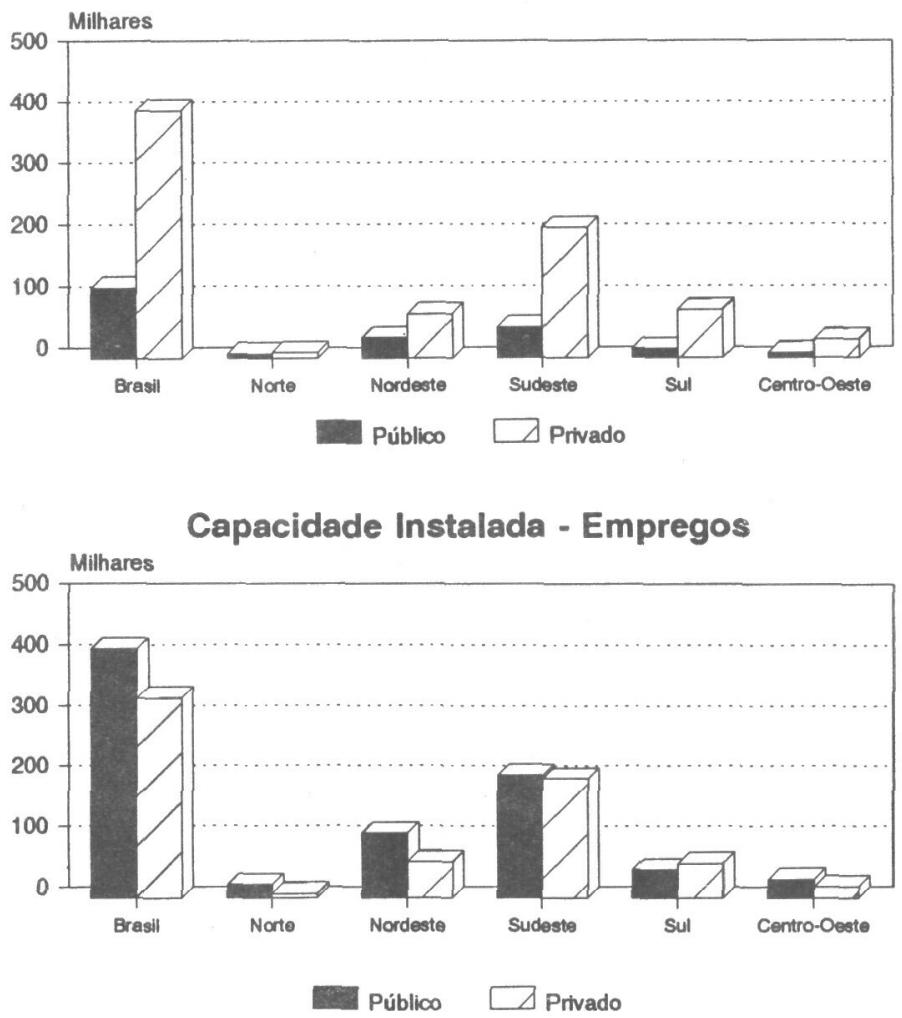

Fonte - 1BGE - AMS/87 